\title{
Utility of Complete Blood Picture for Predicting In-hospital Mortality in Patients with Acute Decompensated Heart Failure with Dilated Cardiomyopathy
}

\author{
Dangeti Malleswara Rao ${ }^{1} \quad$ Garre Indrani $^{1} \quad$ M. RaviKiran ${ }^{1}$ \\ ${ }^{1}$ Department of Cardiology, Nizam's Institute of Medical Sciences \\ (NIMS), Punjagutta, Hyderabad, Telangana, India \\ Indian J Cardiovasc Dis Women-WINCARS 2017;2:44-48. \\ Address for correspondence Dangeti Malleswara Rao, MD, DM, \\ Department of Cardiology, Nizam's Institute of Medical Sciences \\ (NIMS), Punjagutta, Hyderabad 500082, Telangana, India \\ (e-mail: ramakrishnaji83@gmail.com).
}

\begin{abstract}
Keywords

- acute decompensated heart failure

- congestive heart failure

- dilated cardiomyopathy

- mean corpuscular hemoglobin

Background Congestive heart failure (CHF) is one of the leading causes of acute hospital admissions. Despite recent advances in heart failure therapy, prognosis is still poor, rehospitalization rate is very high, and quality of life is worse. It is important to identify patients at increased risk of adverse events. We tried to investigate role of components of complete blood picture on in-hospital mortality in patients hospitalized with heart failure.

Methods It was an observational study of consecutive patients who admitted with a diagnosis of acute decompensated heart failure (ADHF) with dilated cardiomyopathy (DCM) in the our department between January 1, 2016 and December 31, 2016, age above 18 years. Ischemic cardiomyopathy was ruled by doing coronary angiograms either in this admission or previously known. Baseline investigations including complete blood picture were done and the patients were followed up till discharge or in hospital mortality.

Results A total of 74 patients (female:male::24:50) enrolled into the study (mean age $51.86 \pm 13.5$ years) in 12 months. A total of $8(10.8 \%)$ patients died during hospitalization. Among the 74 heart failure patients, 24 (32.5\%) had anemia. Group 1 included patients who died during index hospitalization $(n=8)$ and group 2 comprised patients who were discharged in a stable condition after index hospitalization $(n=66)$. Group 1 patients had low hemoglobin ( $12.34 \pm 2.93$ vs. $14.4 \pm 0.21 \mathrm{~g} / \mathrm{dL}, p=0.000)$ and high leukocyte count $(11,600 \pm 2,780$ vs. $9,047 \pm 3,355$ cells/mcL, $p=0.040)$ with more eosinophils ( $1 \pm 1.06$ vs. $4.16 \pm 3.48 \%, p=0.000)$ and lymphocytes $(20.5 \pm 0.53$ vs. $17.56 \pm 7.45 \%, p=0.002$ ). Regression analysis showed a significant association between low hemoglobin and low packed cell volume (PCV) with in-hospital mortality. Mean corpuscular hemoglobin (MCH) and mean corpuscular volume (MCV) rather than mean corpuscular hemoglobin concentration $(\mathrm{MCHC})$ predicted worse outcome. There was a significantly higher risk of in-hospital mortality with increasing eosinophil count. On the other hand, there was no association between platelet count, total white blood cell (WBC) count, neutrophil, monocyte, or lymphocyte count with clinical outcome. Conclusion Low hemoglobin, low PCV, and high eosinophil count have been shown to predict in-hospital mortality. Complete blood picture can, therefore, be utilized in riskstratifying patients with ADHF due to DCM.
\end{abstract}

Copyright (c) 2017 Women in Cardiology License terms and Related Sciences 


\section{Introduction}

Congestive heart failure (CHF) is the leading cause of acute hospital admissions and one of the main causes of death. ${ }^{1}$ Mortality rates approach $20 \%$ per year in spite of current medical therapy. ${ }^{2}$ However, the clinical course of patients with $\mathrm{CHF}$ is variable.

Understanding what factors relate to subsequent mortality and morbidity may help in identifying which patients need more intense monitoring and therapy.

Several models predict outcome in patients with heart failure (HF), but most of them are very complex and may need wide range of investigations. ${ }^{3}$ The purpose of this study is to assess the impact of components of complete blood picture (CBP) on in-hospital mortality in patients hospitalized with HF due to dilated cardiomyopathy (DCM).

\section{Material and Methods}

The study was conducted in our department of cardiology between January 1, 2016 and December 31, 2016. Seventyfour consecutive patients who were admitted with a diagnosis of acute decompensated heart failure (ADHF) due to DCM and met inclusion criteria were recruited. Patients with ischemic cardiomyopathy were excluded after doing coronary angiogram (CAG), or previous CAG within 6 months showed normal coronaries. The study was approved by the institutional review board. An informed written consent was obtained from the participants before recruiting them in the study.

Patients with medical conditions known to affect hematologic parameters, such as disorders of the hematopoietic system, history of cancer and/or previous treatment with chemotherapy, infection, and chronic inflammatory conditions; and/or histories of glucocorticoid use 3 months before the admission; and acute myocardial infarction or known coronary artery disease (CAD), were excluded. Eligible criteria for the study include any patient with age of at least 18 years; New York Heart Association (NYHA) class II, III, or IV symptoms; and an ejection fraction of $\leq 35 \%$ with normal coronaries.

We also excluded major comorbidities that may have independent influence on in-hospital mortality such as patients with acute and severe renal failure, active hepatic disease, severe pulmonary disease (e.g., chronic obstructive pulmonary disease), and acute infectious disease.

We divided the patients into two groups. Group 1 included patients who died during index hospitalization and group 2 comprised patients who were discharged in a stable condition after index hospitalization. Herein, we assessed the use of the white blood cell (WBC) count and other components of the CBP to predict in-hospital mortality. All patients were subjected to undergo routine investigations including complete blood counts. All data including patient's demographics, medical history, medications, clinical presentation, and electrocardiographic (ECG) and echocardiographic details were obtained. Hematologic parameters on date of admission were taken as parameters to predict in-hospital mortality. All blood samples were examined by the same experienced pathologist. Association between hematologic variables and in-hospital mortality was evaluated.

\section{Statistical Analysis}

Descriptive statistics for data with normal distribution were presented as means and standard deviations from the mean. Comparison between two groups was tested for continuous and dichotomous variables using Student's paired $t$-test and $\mathrm{X}^{2}$, respectively. Regression analysis of survival data based on a Cox proportional-hazards model was used to explain the effect of laboratory values on morbidity and mortality hazard rates. A $p$ value $<0.05$ was considered statistically significant.

\section{Results}

Participants were enrolled in this trial between January 1 , 2016 and December 31, 2016. A total of 74 patients enrolled into the study (mean age $51.86 \pm 13.5$ ). Of these 74 patients, 50 (67.5\%) were males and 24 (32.5\%) were females. History of hypertension was present in 33 (44.6\%) patients and diabetes mellitus (DM) in 25(33.8\%) patients; 22 (29.7\%) patients were smokers ( $\mathbf{-}$ Table $\mathbf{1}$ ).

Mean hemoglobin and packed cell volume (PCV) were $12.56 \pm 2.8 \mathrm{~g} / \mathrm{dL}$ and $37.98 \pm 8.6 \%$, respectively. Among the 74 HF patients, 24 (32.5\%) had anemia. Mean total leucocyte count was 9,323 $\pm 3,376$ cells/mcL whereas mean red blood cell (RBC) count and mean platelet count were $4.39 \pm 0.9$ million cells/mcL and $123230 \pm 33760$ cells/mcL, respectively. The erythrocyte sedimentation rate (ESR) in our patients ranged from 5 to $170 \mathrm{~mm} / \mathrm{h}$ (mean $28.34 \pm 38.7$ ). Low ESR $(<5 \mathrm{~mm}$ ) was found in only seven (9.5\%) patients. Baseline CBP parameters are shown in - Table 2.

Total $8(10.8 \%)$ patients died during hospitalization. Group 1 included patients who died during index hospitalization $(n=8)$ and group 2 comprised patients who were discharged in a stable condition after index hospitalization $(n=66)$. We compared the white blood cell (WBC) count and other components of the $\mathrm{CBP}$ to predict in-hospital mortality ( - Table 3).

Regression analysis showed a significant association between low hemoglobin and low PCV with in-hospital mortality. Mean corpuscular hemoglobin $(\mathrm{MCH})$ and mean corpuscular volume (MCV) rather than mean corpuscular hemoglobin concentration (MCHC) predicted worse outcomes in patients admitted to the hospital with ADHF. There was a significantly higher risk of in-hospital mortality with

Table 1 Demographic features of study population

\begin{tabular}{|l|l|}
\hline Variable & No. \\
\hline Age $(y)$ & $51.86 \pm 13.5$ \\
\hline Total & 74 \\
\hline Females & $24(32.5 \%)$ \\
\hline Hypertension & $33(44.6 \%)$ \\
\hline DM & $25(33.8 \%)$ \\
\hline SM & $22(29.7 \%)$ \\
\hline
\end{tabular}

Abbreviations: DM, diabetes mellitus; SM, smoking. 
Table 2 Baseline complete blood picture

\begin{tabular}{|l|l|l|l|}
\hline Variable & Mean \pm SD & Minimum & Maximum \\
\hline Age (y) & $51.86 \pm 13.5$ & 20 & 80 \\
\hline ESR (mm/h) & $28.34 \pm 38.7$ & 5 & 170 \\
\hline $\begin{array}{l}\text { Packed cell } \\
\text { volume (\%) }\end{array}$ & $37.98 \pm 8.6$ & 20.7 & 56 \\
\hline $\begin{array}{l}\text { Hemoglobin } \\
\text { (g/dL) }\end{array}$ & $12.56 \pm 2.8$ & 7.1 & 18.5 \\
\hline $\begin{array}{l}\text { Red cell count } \\
\text { (million cells/mcL) }\end{array}$ & $4.39 \pm 0.9$ & 2.81 & 6.43 \\
\hline MCH (pg/cell) & $28.91 \pm 2.3$ & 22.7 & 32 \\
\hline MCHC (g/dL) & $33.08 \pm 1.4$ & 29 & 34.8 \\
\hline MCV (fL/cell) & $86.39 \pm 6.1$ & 73.1 & 94.2 \\
\hline $\begin{array}{l}\text { Total leucocytes } \\
\text { (cells/mcL) }\end{array}$ & $9,323 \pm 3,376$ & 4,600 & 16,300 \\
\hline Reticulocyte (\%) & $0.53 \pm 0.1$ & 0.5 & 1 \\
\hline Eosinophil (\%) & $3.82 \pm 3.4$ & 0 & 12 \\
\hline Monocyte (\%) & $5.35 \pm 2.9$ & 0 & 10 \\
\hline Lymphocyte (\%) & $17.88 \pm 7.09$ & 4 & 30 \\
\hline Neutrophil (\%) & $72.74 \pm 8.6$ & 59 & 90 \\
\hline $\begin{array}{l}\text { Platelet count } \\
\text { (cells/mcL) }\end{array}$ & $123,230 \pm 33,760$ & 1.3 & 3.5 \\
\hline
\end{tabular}

Abbreviations: ESR, erythrocyte sedimentation rate; $\mathrm{MCH}$, mean corpuscular hemoglobin; MCHC, mean corpuscular hemoglobin concentration; MCV, mean corpuscular volume; SD, standard deviation.

leucocytosis $(p=0.047)$ with increasing eosinophil count ( $p=0.000$ ). On the other hand, in this trial there was no association between platelet count and neutrophil, monocyte, or lymphocyte count with clinical outcome (-Table 4).
Table 4 Regression analysis

\begin{tabular}{|l|l|l|}
\hline Parameter & $\begin{array}{l}\text { Chi-square } \\
\text { value }\end{array}$ & $p$ Value \\
\hline Age (y) & 0.72 & 0.395 \\
\hline Hemoglobin (g/dL) & 3.97 & 0.046 \\
\hline Red cell count (million cells/mcL) & 0.74 & 0.389 \\
\hline MCH (pg/cell) & 12.26 & 0 \\
\hline MCHC (g/dL) & 0.02 & 0.875 \\
\hline MCV (fL/cell) & 27.84 & 0 \\
\hline Total leucocytes (cells/mcL) & 3.95 & 0.047 \\
\hline Eosinophil (\%) & 10.91 & 0.001 \\
\hline Monocyte (\%) & 0.77 & 0.382 \\
\hline Lymphocyte (\%) & 1.3 & 0.254 \\
\hline Packed cell volume (cells/mcL) & 3.81 & 0.051 \\
\hline Neutrophil (\%) & 0.19 & 0.66 \\
\hline Platelet count & 0 & 0.98 \\
\hline
\end{tabular}

Abbreviations: $\mathrm{MCH}$, mean corpuscular hemoglobin; $\mathrm{MCHC}$, mean corpuscular hemoglobin concentration; MCV, mean corpuscular volume.

\section{Discussion}

In our study, anemia was frequently observed, found in over almost one-third of HF patients. A wide range of anemia prevalence in ADHF has been reported, ranging from $7 \%$ to over $50 \%{ }^{4-11}$ This wide range in prevalence can be attributed to multiple factors, including the use of multiple definitions of anemia. The World Health Organization (WHO) criteria

Table 3 Comparison of completer blood picture parameters in both groups

\begin{tabular}{|l|l|l|l|}
\hline \multirow{2}{*}{ Variable } & Mean \pm SD & \multirow{2}{*}{$p$ Value } \\
\cline { 2 - 3 } & Death & Survive & \\
\hline Number & 8 & 66 & 0.509 \\
\hline Age (y) & $48 \pm 17.1$ & $52.33 \pm 13.12$ & 0.000 \\
\hline Packed cell volume (\%) & $37.33 \pm 8.9$ & $43.4 \pm 1.17$ & 0.000 \\
\hline Hemoglobin (g/dL) & $12.34 \pm 2.93$ & $14.4 \pm 0.21$ & 0.016 \\
\hline Red cell count (million cells/mcL) & $4.35 \pm 0.96$ & $4.65 \pm 0.08$ & 0.000 \\
\hline MCH (pg/cell) & $28.65 \pm 2.28$ & $30.95 \pm 0.05$ & 0.715 \\
\hline MCHC (g/dL) & $33.07 \pm 1.41$ & $33.15 \pm 0.37$ & 0.000 \\
\hline MCV (fL/cell) & $85.54 \pm 5.95$ & $93.35 \pm 0.90$ & 0.040 \\
\hline Total leucocytes (cells/mcL) & $11,600 \pm 2,780$ & $9,047 \pm 3,355$ & 0.000 \\
\hline Eosinophil (\%) & $4.16 \pm 3.48$ & $1 \pm 1.06$ & 0.507 \\
\hline Monocyte (\%) & $4.5 \pm 3.74$ & $5.45 \pm 2.84$ & 0.002 \\
\hline Lymphocyte (\%) & $17.56 \pm 7.45$ & $20.5 \pm 0.53$ & $72.59 \pm 9.09$ \\
\hline Neutrophil (\%) & $74 \pm 2.13$ & $2.34 \pm 0.69$ & 0.301 \\
\hline Platelet count (cells/mcL) & $2.35 \pm 0.16$ & 0.922 \\
\hline
\end{tabular}

Abbreviations: $\mathrm{MCH}$, mean corpuscular hemoglobin; MCHC, mean corpuscular hemoglobin concentration; MCV, mean corpuscular volume; SD, standard deviation. 
were used in the majority of studies. Anemia in HF is considered to develop due to a complex interaction of iron deficiency, kidney disease, and cytokine production, although micronutrient insufficiency and blood loss may contribute. Plasma levels of tumor necrosis factor- $\alpha$ (TNF- $\alpha$ ), interleukin-1, and interleukin-6 are elevated in HF, promoting iron storage by the reticuloendothelial system, likely contributing to the anemia of chronic disease. We did not differentiate anemia on etiologic basis for predicting mortality. Peripheral smear is a useful, inexpensive, widely available tool for the management and prognosis of HF.

Based on our study results, a significant relationship was observed between baseline hemoglobin and PCV and cardiac mortality in patient with ADHF. Anemia is associated with an increased mortality in patients with CHF in numerous previous trials. ${ }^{4-15}$ Several authors speculated about the mechanisms behind the increased mortality risk observed in anemic CHF patients. ${ }^{10,16,17}$ Anemia may lead to an increased workload, resulting from an increased heart rate and stroke volume. In response to the increased workload, the heart undergoes "remodeling" marked by left ventricular hypertrophy and dilation. This eventually may lead to CHF with an increased mortality risk. One interesting finding in this study was MCHC that was not the outcome predictor though MCV and $\mathrm{MCH}$ were one of the outcome predictors. Both $\mathrm{MCH}$ and $\mathrm{MCHC}$ reflect the average hemoglobin content of RBCs in slightly different ways. However, the MCHC, as measured by a multichannel analyzer nowadays, typically results in slightly increased hematocrit. This may explain the fact that MCHC did not predict in-hospital mortality though MCH and MCV did. This has not been documented in previous studies. ${ }^{10,12-17}$

Higher baseline WBC count was associated with worse short-term outcome in few trials, but it is not outcome predictor in the present study. ${ }^{18}$ It is not WBCs as a whole that initiates and perpetuates various maladaptive cascades in HF. It is specific subset of WBCs that have main role in pathophysiology of HF.

Neutrophilia has been shown to be an independent predictor of mortality in patients with ADHF in some of the trials. ${ }^{19-21}$ Most of the above trials did not exclude infection and other comorbidities that may increase neutrophil count.

Elevated monocytes count is an independent predictor of in-hospital mortality in the present study. Ziegler-Heitbrock et al reported that monocyte count is as a mortality predictor in HF patients. ${ }^{22}$ Monocytes have been implicated in mechanisms of progression of atherosclerotic damage in experimental models and in human pathologies. ${ }^{23}$ It is reasonable to hypothesize that selective modulation of monocyte expansion is likely to be relevant for the progression of $\mathrm{CHF}$. Monocyte may provoke damage by infiltrating the failing myocardium and by contributing to the systemic inflammatory processes.

Our result did not suggest that the mortality risk increases with lower lymphocyte count. Thompson et al suggested that total lymphocyte count showed the best correlation and was the best predictor of survival in HF patients. ${ }^{24}$ Charach et al demonstrated that low total lymphocyte counts has an association with increased mortality. ${ }^{25}$ The prognostic value of low total lymphocyte counts was examined in several studies with greater emphasis on increased risk for mortality in HF patients HF. ${ }^{26-28}$ lymphocytopenia is associated with the renin-angiotensin-aldosterone system and the adrenergic nervous system. Elevated adrenaline, angiotensin and cortisol levels have a proapoptotic effect on lymphocytes. Furthermore, all these hormones elevate the neutrophil count and will cause relative lymphocytopenia. Reason for this contradictory finding may be differences in selection criteria from previous trials.

This study findings do not support the classic teaching that the ESR is characteristically low in patients with CHF as only $10 \%$ of subsets have low ESR. ${ }^{29}$ Low ESR is not an independent predictor of mortality in our study. ESR $<5$ $\mathrm{mm} / \mathrm{h}$ is defined as low ESR in the present study. Patients who had low ESR have worse clinical outcomes according to Eisenberg et al. ${ }^{31}$ Haber et al and Eisenberg speculated that during periods of acute decompensation or when the clinical syndrome of right-sided HF ensues in patients with longstanding left ventricular failure, right atrial pressure rises, and hepatic congestion develops. ${ }^{30,31}$ This increase in intrahepatic sinusoidal pressure might impair the formation or accelerate the degradation of fibrinogen. As we excluded patients with elevated liver enzymes more than three times in the present study irrespective of etiology, we might have missed patients with severe hepatic congestion that was postulated to cause low ESR.

Higher eosinophil count was found to have association with in-hospital mortality. This is not documented in previous studies. We hypothesized that this finding can be attributed to higher incidence of eosinophilic endomyocarditis due to dobutamine allergy as patients with severe disease are more likely to receive higher doses of dobutamine. ${ }^{32}$

\section{Limitations}

The major limitation of the present study was the relatively small numbers of patients who participated. Our study population of patients with advanced CHF may not reflect the characteristics of CHF patients in the general population. N-terminal of pro-brain natriuretic peptide (NT-proBNP) that has a proven value in prognostication of HF patients must have been used to compare predictive value of hematologic parameters.

\section{Conclusion}

In patients with acute HF, certain components of complete blood count can predict in-hospital mortality. Accordingly, CBP might be a very useful marker that can be utilized in riskstratifying patients with ADHF. Moreover, it is inexpensive and easy to perform. Nonetheless, further larger-scale and multicenter studies were needed to confirm these findings.

\section{References}

1 Dargie HJ, McMurray JJ. Diagnosis and management of heart failure. BMJ 1994;308(6924):321-328

2 American Heart Association. Heart Disease and Stroke Statistics2003 Update. Dallas, TX: American Heart Association; 2003 
3 Levy WC, Mozaffarian D, Linker DT, et al. The Seattle Heart Failure Model: prediction of survival in heart failure. Circulation 2006; 113(11):1424-1433

4 Anand I, McMurray JJ, Whitmore J, et al. Anemia and its relationship to clinical outcome in heart failure. Circulation 2004;110 (02):149-154

5 Ezekowitz JA, McAlister FA, Armstrong PW. Anemia is common in heart failure and is associated with poor outcomes: insights from a cohort of 12065 patients with new-onset heart failure. Circulation 2003;107(02):223-225

6 Go AS, Yang J, Ackerson LM, et al. Hemoglobin level, chronic kidney disease, and the risks of death and hospitalization in adults with chronic heart failure: the Anemia in Chronic Heart Failure: Outcomes and Resource Utilization (ANCHOR) study. Circulation 2006;113(23):2713-2723

7 Kosiborod M, Curtis JP, Wang Y, et al. Anemia and outcomes in patients with heart failure: a study from the National Heart Care Project. Arch Intern Med 2005;165(19):2237-2244

8 Komajda M, Anker SD, Charlesworth A, et al. The impact of new onset anaemia on morbidity and mortality in chronic heart failure: results from COMET. Eur Heart J 2006;27(12):1440-1446

9 Schou M, Gustafsson F, Kistorp CN, Corell P, Kjaer A, Hildebrandt PR. Prognostic usefulness of anemia and $\mathrm{N}$-terminal pro-brain natriuretic peptide in outpatients with systolic heart failure. Am J Cardiol 2007;100(10):1571-1576

10 Tanner H, Moschovitis G, Kuster GM, et al. The prevalence of anemia in chronic heart failure. Int J Cardiol 2002;86(01): 115-121

11 Rosolova H, Cech J, Simon J, et al. Short to long term mortality of patients hospitalised with heart failure in the Czech Republic-a report from the EuroHeart Failure Survey. Eur J Heart Fail 2005;7 (05):780-783

12 McClellan WM, Flanders WD, Langston RD, Jurkovitz C, Presley R. Anemia and renal insufficiency are independent risk factors for death among patients with congestive heart failure admitted to community hospitals: a population-based study. J Am Soc Nephrol 2002;13(07):1928-1936

13 Silverberg DS, Wexler D, Blum M, et al. The use of subcutaneous erythropoietin and intravenous iron for the treatment of the anemia of severe, resistant congestive heart failure improves cardiac and renal function and functional cardiac class, and markedly reduces hospitalizations. J Am Coll Cardiol 2000;35(07):1737-1744

14 Horwich TB, Fonarow GC, Hamilton MA, MacLellan WR, Borenstein J. Anemia is associated with worse symptoms, greater impairment in functional capacity and a significant increase in mortality in patients with advanced heart failure. J Am Coll Cardiol 2002;39(11):1780-1786

15 Charlot M, Torp-Pedersen C, Valeur N, Seibæk M, Weeke P, Køber $\mathrm{L}$; MetteCharlot. Anaemia and long term mortality in heart failure patients: a retrospective study. Open Cardiovasc Med J 2010; 4:173-177

16 Akhter MW, Aronson D, Bitar F, et al. Effect of elevated admission serum creatinine and its worsening on outcome in hospitalized patients with decompensated heart failure. Am J Cardiol 2004; 94(07):957-960
17 Varat MA, Adolph RJ, Fowler NO. Cardiovascular effects of anemia. Am Heart J 1972;83(03):415-426

18 Cooper HA, Exner DV, Waclawiw MA, Domanski MJ. White blood cell count and mortality in patients with ischemic and nonischemic left ventricular systolic dysfunction (an analysis of the Studies Of Left Ventricular Dysfunction [SOLVD]). Am J Cardiol 1999;84(03):252-257

19 Acanfora D, Gheorghiade M, Trojano L, et al. Relative lymphocyte count: a prognostic indicator of mortality in elderly patients with congestive heart failure. Am Heart J 2001;142(01):167-173

20 Uthamalingam S, Patvardhan EA, Subramanian S, et al. Utility of the neutrophil to lymphocyte ratio in predicting long-term outcomes in acute decompensated heart failure. Am J Cardiol 2011; 107(03):433-438

21 Moiseyev VS, Põder P, Andrejevs N, et al; RUSSLAN Study Investigators. Safety and efficacy of a novel calcium sensitizer, levosimendan, in patients with left ventricular failure due to an acute myocardial infarction. A randomized, placebo-controlled, doubleblind study (RUSSLAN). Eur Heart J 2002;23(18):1422-1432

22 Ziegler-Heitbrock HW. Heterogeneity of human blood monocytes: the CD14+ CD16+ subpopulation. Immunol Today 1996; 17(09):424-428

23 Mestas J, Ley K. Monocyte-endothelial cell interactions in the development of atherosclerosis. Trends Cardiovasc Med 2008;18 (06):228-232

24 Thomson SP, McMahon LJ, Nugent CA. Endogenous cortisol: a regulator of the number of lymphocytes in peripheral blood. Clin Immunol Immunopathol 1980;17(04):506-514

25 Charach G, Grosskopf I, Roth A, et al. Usefulness of total lymphocyte count as predictor of outcome in patients with chronic heart failure. Am J Cardiol 2011;107(09):1353-1356

26 Marra S, Hoffman-Goetz L. Beta-adrenergic receptor blockade during exercise decreases intestinal lymphocyte apoptosis but not cell loss in mice. Can J Physiol Pharmacol 2004;82(07): 465-473

27 Abrams MT, Robertson NM, Yoon K, Wickstrom E. Inhibition of glucocorticoid-induced apoptosis by targeting the major splice variants of BIM mRNA with small interfering RNA and short hairpin RNA. J Biol Chem 2004;279(53):55809-55817

28 Anker SD, Chua TP, Ponikowski P, et al. Hormonal changes and catabolic/anabolic imbalance in chronic heart failure and their importance for cardiac cachexia. Circulation 1997;96(02): 526-534

29 Bedell SE, Bush BT. Erythrocyte sedimentation rate. From folklore to facts. Am J Med 1985;78(6 Pt 1):1001-1009

30 Haber HL, Leavy JA, Kessler PD, Kukin ML, Gottlieb SS, Packer M. The erythrocyte sedimentation rate in congestive heart failure. N Engl J Med 1991;324(06):353-358

31 Eisenberg S. Changes in blood viscosity, hematocrit value, and fibrinogen concentration in subjects with congestive heart failure. Circulation 1964;30:686-693

32 Raje VP, Lewis NP, Katlaps GJ, Quader MA, Shah KB, Mankad AK. Dobutamine induced eosinophilic myocarditis and right heart failure requiring emergent biventricular assist device implantation. ASAIO J 2015;61(02):213-215 